\title{
Quimicon, jogo educacional para a aprendizagem da Tabela Periódica no Ensino Médio
}

\author{
Eduardo Jorge Lira A. da Silva', José Carlos da Silva Duarte Filho', Danielle \\ Pompeu Noronha Pontes ${ }^{1}$
}
${ }^{1}$ Escola Superior de Tecnologia (EST) - Universidade do Estado do Amazonas (UEA)
Av. Darcy Vargas, 1200, Parque Dez - Manaus - AM - Brasil
eduardu.silva@hotmail.com, carlos.duarte.jc@gmail.com,
dnoronha@uea.edu.br

\begin{abstract}
Resumo. Este artigo apresenta a proposta do aplicativo Quimicon, um jogo educativo destinado para aprimoramento dos estudos de química sobre a tabela periódica. Destinado para as series iniciais do ensino médio e para aqueles que estejam estudando o conteúdo em sala de aula, independente da serie. Consiste na associação de elementos químicos com personagens animados e a apreensão de conhecimentos fundamentais sobre os elementos por meio de sistemas de batalha, criação de elementos através das camadas eletrônicas e na coleção dos elementos atômicos para o preenchimento total da tabela periódica.
\end{abstract}

\section{Cenário de uso}

O uso do computador como máquina de aprendizagem consiste na informatização dos métodos de ensino tradicionais. Do ponto de vista pedagógico esse é o paradigma Instrucionista (Valente, 1993). Com base nesta teoria, o computador torna-se responsável por viabilizar a aprendizagem do aluno. A teoria Construcionista também faz uso do computador e proporciona a construção da aprendizagem, porém a figura do professor é necessária para realizar a mediação entre a máquina e o estudante. A aprendizagem significativa é o processo de obter uma nova informação, ou uma nova aprendizagem a partir dos conhecimentos anteriores. As novas informações interagem com as anteriores através de uma estrutura cognitiva, funcionando como uma hierarquia de conceitos. Para Ausubel (1963), a aprendizagem significativa é o mecanismo humano, por excelência, para adquirir e armazenar a vasta quantidade de ideias e informações representadas em qualquer campo de conhecimento.

O projeto tem como base pedagógica o Instrucionismo o Construcionismo, e a teoria da aprendizagem significativa, pois a ferramenta possui aspectos presentes em cada uma dessas teorias.

A ferramenta proposta trata-se de um Jogo, intitulado de Quimicon que busca transmitir conceitos básicos de cada elemento da tabela periódica. Alunos que estão tendo contato com a química pela primeira vez, podem encontrar dificuldades em assimilar os elementos da tabela, seus nomes, números atômicos e propriedades, Alves; Souza; Moises (2016). Muitas vezes o que dificulta a aprendizagem dos conceitos é a metodologia empregada pelo professor que se baseia na memorização de símbolos, nomes, propriedades, etc., o que não garante aprendizagem significativa do conteúdo em questão, Ferreira; Silva; Silva, (2012). 
Ao envolver química com jogos digitais, este trabalho visa aprofundar os conceitos já vistos em sala de aula sobre os elementos da tabela de forma divertida e atrativa. O aplicativo é dirigido para alunos que estejam cursando o ensino médio ou para aqueles que estão tendo contato com a disciplina de química.

O jogo Quimicon foi desenvolvido com o propósito de auxiliar no processo de ensino-aprendizagem dos conceitos essenciais necessários para a compreensão e leitura da tabela periódica dos elementos. A aprendizagem ocorre através da associação de elementos do jogo com elementos do conteúdo, permitindo uma aprendizagem significativa. É esperado que o aplicativo proporcione aos alunos uma autonomia por parte da construção do conhecimento e torne um pouco mais claro o entendimento de alguns princípios fundamentais da química.

\subsection{Possibilidades de modelos de negócio}

Inicialmente a solução apresentada tem foco acadêmico e busca proporcionar maior engajamento e interesse no estudo de química aplicado a área de informática na educação. Entretanto, no futuro, será feita a distribuição e lançamento nas lojas de aplicativos para android, como a Google Play. Considerando que o aplicativo pode ser utilizado dentro e fora da sala de aula, com auxílio ou não do professor. O jogo pode ser aplicado como um objeto de aprendizagem para revisão e fixação de conteúdo, assim como pode ser jogado apenas para fins de diversão e entretenimento.

\section{Desenvolvimento}

O jogo Quimicon foi desenvolvido e organizado na engine de desenvolvimento de aplicativos e jogos Unity 3D. A versão utilizada do software Unity foi a versão 5.6. A Unity é uma ferramenta que permite o desenvolvimento tanto de jogos $2 \mathrm{D}$ quanto $3 \mathrm{D}$, com um potente mecanismo de renderização totalmente integrado e que possui uma versão gratuita a qual foi utilizada para a criação do presente aplicativo.

A linguagem de programação utilizada no desenvolvimento do jogo foi à linguagem C\#. O jogo Quimicon foi desenvolvido inicialmente para as plataformas de dispositivos móveis com Sistema operacional Android, na versão mínima 4.4. Portanto, é possível jogar Quimicon em celulares smarthphone e tablets. O processo de desenvolvimento do aplicativo seguiu as etapas descritas no diagrama 01 :

Diagrama 01 - Diagrama de Atividade sobre as etapas de Desenvolvimento

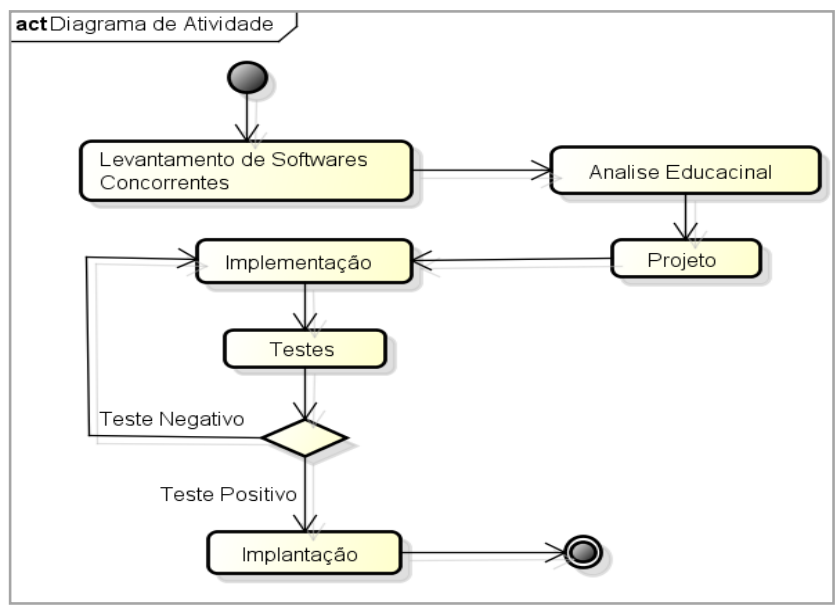


VI Congresso Brasileiro de Informática na Educação (CBIE 2017)

Anais dos Workshops do VI Congresso Brasileiro de Informática na Educação (WCBIE 2017)

\subsection{Levantamento de Softwares Concorrentes}

A fase de levantamento de Softwares Concorrentes foi a primeira a ser realizada após a solicitação e ideação do aplicativo aqui descrito. Alguns dos aplicativos encontrados possuem características que serviram de inspiração para o desenvolvimento do jogo aqui relatado. Dentro os jogos selecionados como inspiração/concorrente estão: o jogo de cartas Super Trunfo, os jogos digitais mobile como Pokémon Go, Átomas e Xenubi Tabela periódica.

Super Trunfo é um jogo de cartas colecionáveis que serviu como base inspiratória no desenvolvimento de parte da mecânica do Quimicon. O jogo consiste em uma batalha entre as cartas dos adversários, o primeiro a jogar escolhe entre as informações contidas em sua primeira carta, julgando possuir um valor maior que a carta dos adversários na mesma informação. A carta com o maior valor vence e o vencedor fica com as cartas dos jogadores que perderam, o objetivo é obter todas as cartas adversárias.

Pokémon Go é jogo para smartphones desenvolvido por uma colaboração entre a Niantic, Inc., a Nintendo e a The Pokémon Company com o objetivo de capturar Pokémon para colecionar e para usá-los em batalhas contra outros Pokémons.

Átomas é um jogo da Sirnic Games disponível para Smartphone para o ensino de Química. O conteúdo abordado é a fusão de átomos para a criação de outros, seu objetivo principal é criar os elementos valiosos como ouro, platina e prata.

Xenubi - Tabela periódica é um jogo destinado a estudantes de Química que estejam aprendendo sobre as propriedades da tabela periódica. O jogo permite ao aluno exercitar seu conhecimento quanto à relação das propriedades de um elemento químico e sua posição na tabela periódica (Xenubi, 2016).

Quimicon tem como objetivo a aprendizagem de Química e assim como o Xenubi permite ao jogador aprender sobre as propriedades da tabela periódica. Possui uma mecânica fácil e com algumas das características dos jogos aqui descritos. De Pokémon Go adquiriu a ideia de colecionar os elementos conquistados (ou criados) e usa -lós para batalhar, de Átomas a influência foi do designer e da proposta de criar novos átomos. As batalhas são inspiradas em Super Trunfo e assim como em Xenubi os valores usados são referentes às principais características e propriedades apresentados na Tabela Periódica.

\subsection{Análise Educacional}

A Análise Educacional equivale ao estudo das abordagens teóricas presentes em cada um dos jogos concorrentes e no jogo proposto para desenvolvimento.

Foi investigada a qual tipo de software melhor se encaixa em cada um dos citados, com isso mais os objetivos e a mecânica do jogo proposto foi definida qual a base pedagógica mais se adequa ao projeto. $\mathrm{E}$ como citado $\mathrm{o}$ instrucionismo $\mathrm{o}$ Construcionismo, e a teoria da aprendizagem significativa fundamentam o desenvolvimento do aplicativo Quimicon.

\subsection{Projeto}

Após a definição da mecânica e da base pedagógica do projeto, esta fase constitui-se da delimitação dos aspectos computacionais como arquitetura do sistema, linguagem de programação, escolha da engine a ser usada e de padrões de interface gráfica. Também 
VI Congresso Brasileiro de Informática na Educação (CBIE 2017)

Anais dos Workshops do VI Congresso Brasileiro de Informática na Educação (WCBIE 2017)

faz - se uso da prototipagem, com a criação de protótipos de baixa confiabilidade para fazer análise das funcionalidades do sistema.

O motor de jogo (engine) escolhido para o desenvolvimento do Quimicon foi a Unity que é uma IDE para a criação de jogos criada pela Unity Technologies.

\subsection{Implementação}

A implementação é a fase de criação e execução do código fonte. É quando são implementados de fato as funcionalidades definidas, e para a validação dessas funcionalidades também são criados protótipos de alta confiabilidade que vez ou outra passam por teste.

\subsection{Testes}

Após a implementação ou mesmo em meio ao processo de implementação são realizados alguns testes. Dentre os principais temos:

- Teste da caixa preta que verifica o código, para conferir se as entradas e saídas estão de acordo com o desejado.

- Teste Funcional confere se o software está seguindo as funcionalidades definidas.

\subsection{Implantação}

Por fim, após conclusão e aprovação do sistema, a implementação consiste na instalação do aplicativo no ambiente do usuário, ou a divulgação do mesmo assim como a disponibilização para download.

\section{Apresentação do Software}

O software educacional Quimicon, busca exercitar, estimular e ajudar na aprendizagem de conhecimentos básicos e fundamentais necessários para a compreensão e leitura da tabela periódica dos elementos químicos, tem como principal objetivo o ensino/aprendizagem da tabela periódica e seus elementos, através de métodos gameficados. O jogo possui uma interface com cores fortes e vibrantes e elementos visuais atrativos que facilitam o entendimento do usuário.

O diagrama 02 relata o estado do jogador em casa tela do jogo, quais possíveis funções ele pode acessar partindo de uma determinada situação. O jogo possui uma interface simples, possibilitando ao usuário navegar por toda aplicação sem maiores dificuldades.

Diagrama 02 - Diagrama de Estado

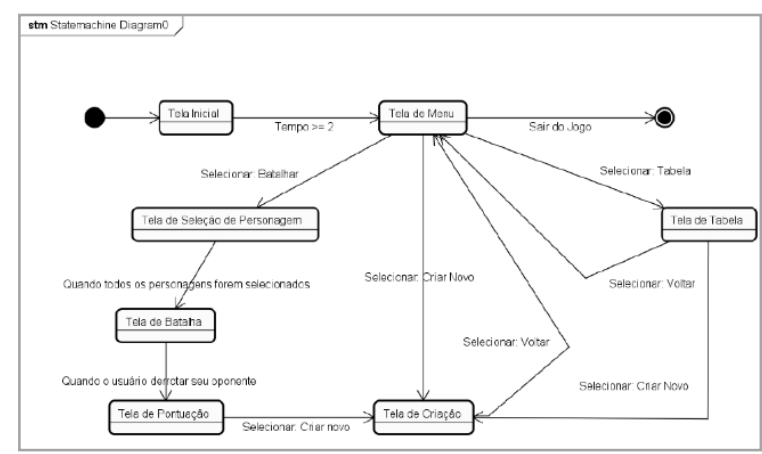


VI Congresso Brasileiro de Informática na Educação (CBIE 2017)

Anais dos Workshops do VI Congresso Brasileiro de Informática na Educação (WCBIE 2017)

\subsection{Conceito do Jogo}

No Quimicon os elementos da tabela são representados como personagens animados, figura 01, cada personagem possui as propriedades do elemento químico que ele representa. $\mathrm{O}$ jogo consiste em batalhas por turnos entre os elementos. Os ataques são representados por perguntas referentes ao elemento inimigo. Por exemplo, o jogador esta em batalha contra o elemento Hélio, por tanto são apresentadas perguntas sobre as especificidades do Hélio, caso a resposta esteja correta, os elementos do jogador atacam o inimigo e este perde uma vida. A condição de vitória consiste em o jogador acertar quatro questões, o que significa que o inimigo foi atacado quatro vezes, perdendo assim todas as suas vidas. Caso o jogador erre a pergunta, o elemento inimigo realiza o ataque e um dos elementos do jogador é eliminado. A condição de derrota consiste na perca dos três elementos do usuário.

Quando a vitória é alcançada, como recompensa é concedida alguns elétrons que ficarão sendo acumulados ao longo das batalhas até que o jogador os use para criar outros elementos. A criação desses elementos representa a distribuição correta de elétrons nas camadas eletrônicas. Por exemplo, se o jogador conseguiu com as batalhas acumular 36 elétrons, ele pode criar elementos que tenham até 36 elétrons distribuídos nas camadas eletrônicas, podendo criar até o elemento Criptônio e para isso basta que o jogador faça a distribuição eletrônica de forma correta.

Os elementos criados são usados nas batalhas e são armazenados na tabela periódica pessoal do jogador que tem como principal objetivo completar sua tabela com todos os elementos, para isso ele precisa vencer as batalhas para obter elétrons e assim criar novos e mais fortes elementos (personagens).

Figura 01 - Os elementos representados por personagens animados da esquerda para a direita temos: Boro, Oxigênio, Hélio e Césio.

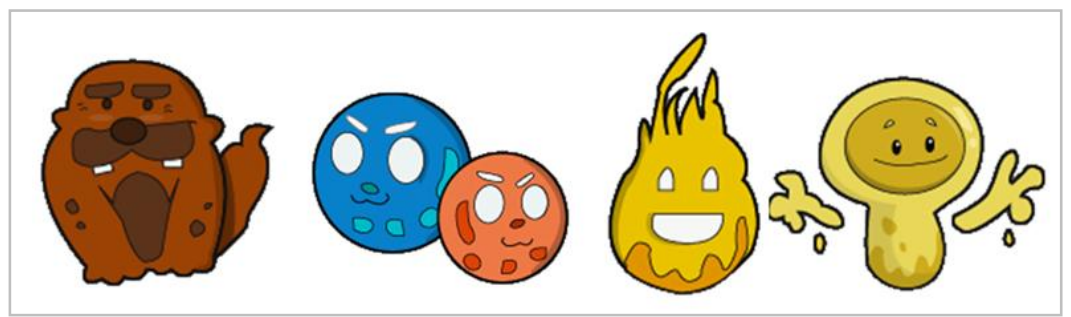

\subsection{Mecânica do Jogo}

O jogo é divido em três condições: Batalha, Criação e Tabela e possuem acesso direto na tela inicial. A opção batalha acessada por meio do botão Batalha direciona o jogador para um mapa no qual estão ordenados por ordem crescente os elementos da tabela (a atual versão possui um total de treze elementos) e estes encontram-se bloqueados (exceto o primeiro) e só são desbloqueados quando o elemento anterior for vencido. A vitória é alcançada respondendo corretamente a questões sobre o elemento inimigo, em caso de resposta errado o inimigo leva vantagem, eliminando os elementos do jogador, até não sobrar nenhum. 
Figura 02 - Mapa para Batalhas

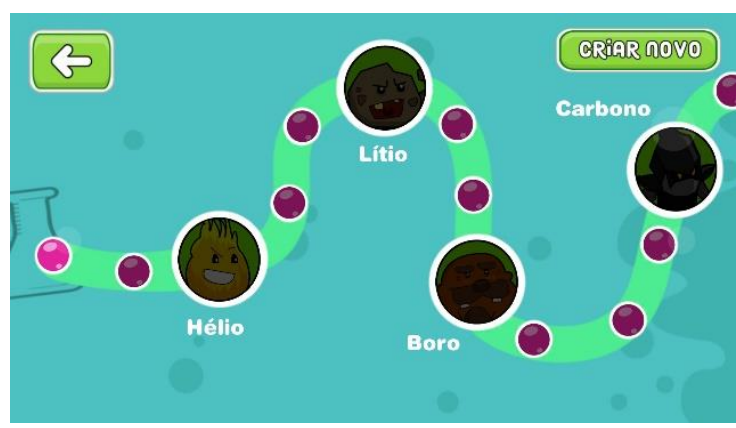

A condição de Criação é acessada pelo botão Criar Novo situado na tela inicial e na tela da Tabela. A tela de criação mostra a quantidade de elétrons acumulados e as sete camadas eletrônicas que os elementos podem ter. O objetivo é usar os elétrons acumulados para criar outro elemento, para isso basta fazer a distribuição eletrônica do elemento desejado, se a distribuição estiver correta e a quantidade de elétrons distribuídos for menor ou igual a quantidade de elétrons acumulados, um novo elemento é criado e este elemento é automaticamente liberado na Tabela e para uso nas batalhas.

A condição de Tabela é acessada clicando no botão Tabela na tela inicial e/ou na tela de criação. A tela da Tabela representa a tabela periódica pessoal do jogador, nela estão todos os elementos criados e que são usados para as batalhas. Nesta tela também é possível conhecer um pouco sobre cada um dos elementos armazenados, pois basta clicar no elemento que uma tela com as informações essências é apresentada.

Para melhor entendimento e visualização do aplicativo basta acessar o link para o vídeo demonstrativo do aplicativo: https://youtu.be/4nSgeYWDJMo

\subsection{Descrição das Telas do Quimicon}

A tela inicial do software apresenta o menu principal figura 03, no qual contém além do logotipo, quatro botões de jogabilidade, sendo eles: Batalha, Tabela, Criar Novo, Sair, mais dois botões de acesso rápido, alterar volume e informações, referentes aos desenvolvedores e responsáveis pelo projeto.

Figura 03 - Tela Inicial/ Menu Principal

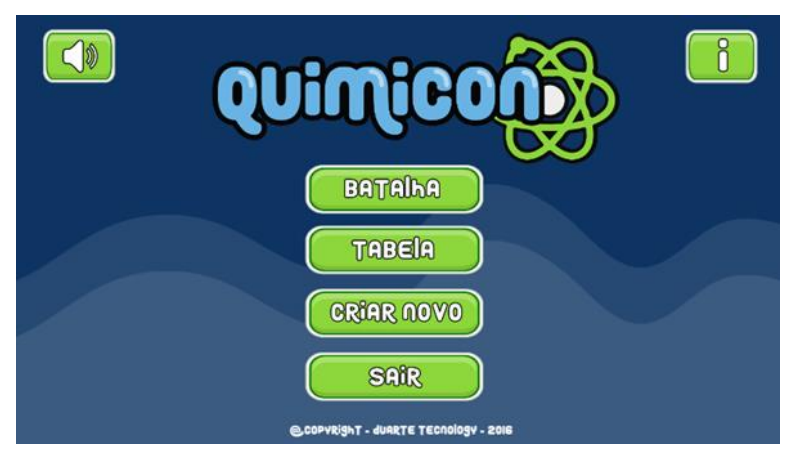

A tela da Tabela é acessada pelo botão Tabela e a tabela periódica é composta pelos elementos criados pelo usuário. Cada elemento é representado por um personagem animado. Os elementos em formatos de silhueta ainda não pertencem à tabela pelo fato de não terem sidos criados, os elementos criados e disponíveis estão coloridos, figura 04. 
VI Congresso Brasileiro de Informática na Educação (CBIE 2017)

Anais dos Workshops do VI Congresso Brasileiro de Informática na Educação (WCBIE 2017)

Os elementos desbloqueados oferecem algumas informações básicas sobre o elemento, figura 5.

Figura 04 - Tela da Tabela

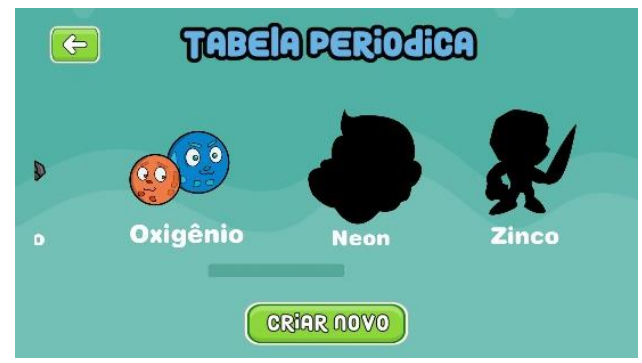

Figura 05 - Tela de informações do elemento do elemento Carbono

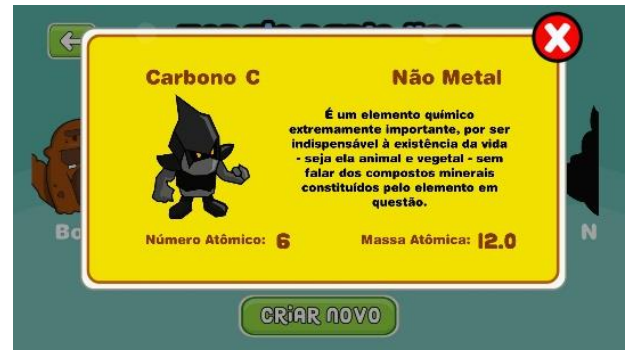

A figura 06 representa a tela de Escolha dos elementos que serão os lutadores. Os elementos que podem ser escolhidos são aqueles disponíveis (desbloqueados) na Tabela. Os elementos escolhidos são separados e ao clicar em Batalhar a tela do combate é apresentada dando inicio ao embate, ao clicar em zerar os elementos escolhidos desaparecem e é preciso escolher novamente.

A figura 07 representa o inicio do combate. Os embates ocorrem por meio das respostas dados as perguntas que são apresentadas sobre o elemento inimigo. Cada resposta certa significa um ataque no inimigo, causando-lhe danos, cada resposta errada o inimigo ataque e elimina um elemento do usuário.

Figura 06 - Tela de Escolha dos elementos

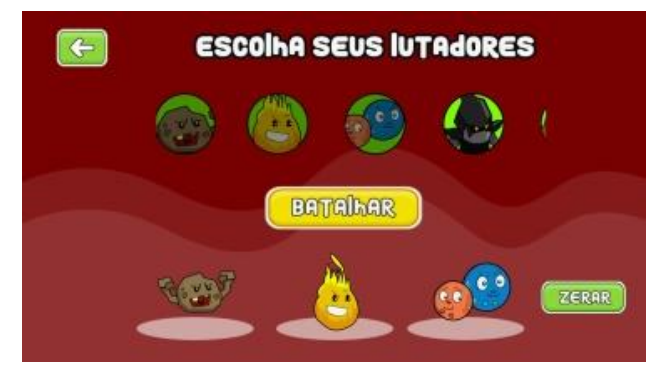

Figura 07 - Tela de Combate

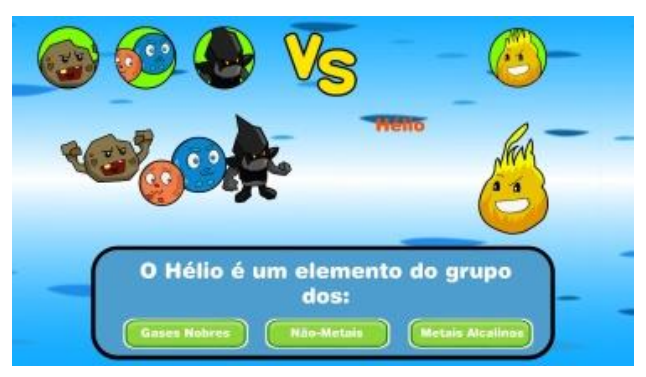

botão Criar Novo é referente à tela de criação de novos elementos figura 08, esta tela apresenta a quantidade de elétrons acumulados e as camadas eletrônicas. Quando o novo elemento é criado ele também é apresentado.

Figura 08 - Tela de Criação

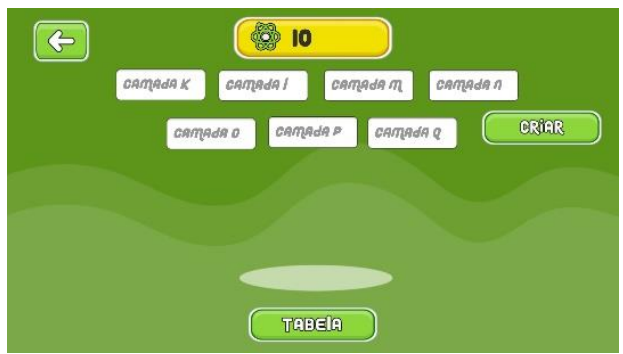


VI Congresso Brasileiro de Informática na Educação (CBIE 2017)

Anais dos Workshops do VI Congresso Brasileiro de Informática na Educação (WCBIE 2017)

\section{Trabalhos Futuros}

A atual versão do protótipo contém apenas treze elementos da tabela periódica, objetivando apresentação da funcionalidade e jogabilidade da ferramenta. A próxima versão que já esta em processo de produção contará com todos os elementos presentes até o momento na tabela.

Também se pretende, com atualizações, acrescentar mais perguntas e maiores informações sobre cada elemento. Outra expectativa para futuras versões da ferramenta é a implementação para suporte multiplayer, para os jogadores poderem interagir entre si, por meio de uma conexão coma internet. Permitindo combates entre jogadores e a troca de elementos, porém isso depende da infraestrutura e da arquitetura do aplicativo e dos sistemas envolvidos.

\section{Considerações finais}

A apresentação do software educativo possibilitou uma nova metodologia de ensinoaprendizagem aos alunos e professores do ensino médio. Baseou-se em conhecimentos na área de educação e computação.

A coleta de resultados proveniente da utilização do software em sala de aula será feita antes, durante e após a aplicação do software. Portanto, a submissão de um jogo na disciplina de química veio a melhorar o desempenho da matéria em sala de aula visando uma adequação por parte do professor e dos alunos fazendo com que haja interação e aprendizagem.

\section{Referências}

AUSUBEL, D.P. (1963). The psychology of meaningful verbal learning. New York, Grune and Stratton.

ALVES, G.; SOUZA, E.; MOISES, P. Química Run: Uma Ferramenta Lúdico-Educativa no Ensino de Química. n. Cbie, p. 701, 2016.

FERREIRA, E.A, GODOI, T.A; DA SILVA, T. P; Aplicação de jogos lúdicos para o ensino de química : auxilio nas aulas sobre tabela periódica. 2012.

VALENTE, J. A. (1993). Por que o computador na educação. Computadores e conhecimento: repensando a educação. Campinas: Unicamp/Nied, 24-44.

POKEMON GO. Niantic Inc. Disponível em: <https://play.google.com/store/apps>. Acesso em 10. Set. 2016.

XENUBI - TABELA PERIÓDICA. Convertiva Mobile. Disponível em: $<$ https://play.google.com/store/apps $>$. Acesso em 20. Set. 2016.

ATOMAS. Sirnic. Disponível em: <https://play.google.com/store/apps>. Acesso em 20. Set.2016. 